\title{
Food Processing: The Meat We Eat ${ }^{1}$
}

\author{
Erica L. Bub, Keith Schneider, Chad Carr, and Matt Hersom²
}

Recently, the media has focused on certain meat products, giving them names such as "pink slime" and "meat glue." The names of these products might have many people wondering what we are eating and how the meat we eat is produced. Part of being a good consumer is learning about what you eat, from how the food is made to whether the food is safe. This publication discusses the facts about meat processing so you can make knowledgeable decisions about the meat you eat.

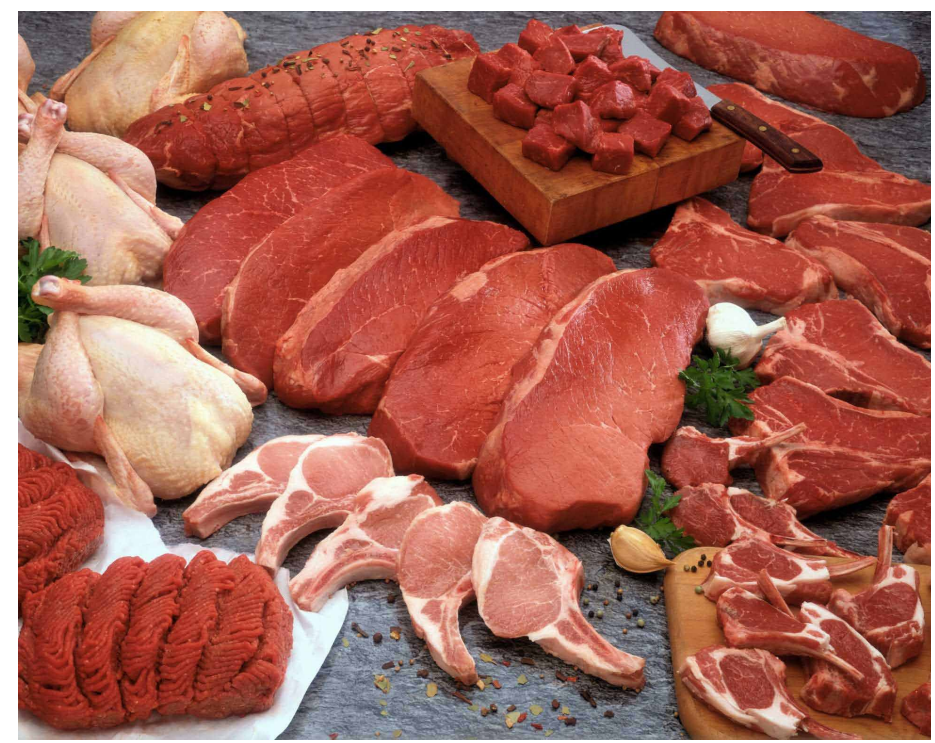

Figure 1. All meat sold in the United States must meet USDA-FSIS inspection standards, including any meat that is processed. Credits: Jupiterimages, (c) Getty Images.

\section{Meat Processing}

All of the meat we eat is butchered, packaged, and prepared in some form or another. This processing occurs at meat processing facilities under microbiologically sanitary conditions (USDA-FSIS 2012a). Some meat products (e.g., hot dogs and chicken nuggets) are more processed than others (e.g., steaks and roasts). The methods used to produce these further-processed products are designed to improve efficiency and product yield for processors and to improve the eating quality, value, and convenience of products for consumers.

The United States government has inspection standards for all meat and poultry products to ensure the safety, wholesomeness, and accurate labeling of these products. The United States Department of Agriculture's (USDA) Food Safety and Inspection Service (FSIS) regulates meat and poultry inspection (USDA-FSIS 2012a). FSIS ensures humane handling and slaughter of animals, inspects all animal carcasses, and sets and verifies food safety standards in meat and poultry processing facilities.

Only meat from animals slaughtered under USDA-FSIS inspection may be sold as food in the United States (USDAFSIS 2012a). This includes meat imported from other countries, as FSIS ensures imported red meat and poultry receive inspection equivalent to the process used for U.S. products (USDA-FSIS 2009).

1. This document is AN283, one of a series of the Department of Animal Sciences, Florida Cooperative Extension Service, Institute of Food and Agricultural Sciences, University of Florida. Original publication date December 2012. Please visit the EDIS website at http://edis.ifas.ufl.edu.

2. Erica L. Bub, dietetic intern, Master of Science-Dietetic Internship Program, Food Science and Human Nutrition Department; Keith Schneider, PhD, professor, Food Science and Human Nutrition Department; Chad Carr, PhD, assistant professor, Department of Animal Sciences; and Matt Hersom, PhD, associate professor, Department of Animal Sciences; Florida Cooperative Extension Service, Institute of Food and Agricultural Sciences, University of Florida, Gainesville, FL 32611. 
Ingredients and processing aids used in or on meat and poultry products also must be approved. The Food and Drug Administration (FDA) must either approve a product prior to its use, or it must be generally recognized as safe (GRAS) for its intended use (US FDA 2012). Currently, ingredients or processing aids may be declared as GRAS through documented scientific evidence (US FDA 2012). These regulations exist to protect public health.

\section{Lean Finely-Textured Beef}

Beef carcasses are cut and trimmed into pieces with a given level of external fat at the processing plant. Those pieces of external fat and lean generated from this process are called trimmings (Berry 1980). These trimmings are used to manufacture the product that the media and some people call "pink slime," which is known as lean finely-textured beef (LFTB; Roth 1978) or finely-textured beef (FTB; Schaefer, James, and Rempe 1995). Advances in technology have made it possible for processors to sustainably use those trimmings instead of throwing them away.

To make LFTB and FTB, the beef trimmings are heated and spun quickly in a process called centrifugation. This separates the lean meat from the fat, leaving a very lean meat product. The lean meat is then treated with either gaseous ammonia (Roth 1978) or citric acid (Schaefer, James, and Rempe 1995), both of which kill bacteria by creating an environment unsuitable for their survival (Greene 2012).

The USDA has approved the use of both of these treatments in beef production as processing aids, according to the Code of Federal Regulations (quoted in USDA-FSIS 2008). According to the FDA, ammonium hydroxide and citric acid are considered processing aids used to enhance a food's appeal or utility. Food processing aids are not required to be labeled because they do not technically alter the composition of the food.

Many people have likely eaten LFTB or FTB at some point. These products are frozen, and distributed to ground beef manufacturers and included at up to $20 \%$ of the final blend with traditional pieces of lean and fat in commercial ground beef production (BPI 2012; Cargill Meat Solutions 2012). These products are also frequently used in the production of lunch meats and sausages.

\section{Intact and Non-Intact Red Meat Products}

A carcass is portioned into large wholesale cuts that can later be cut into the pieces you find in the grocery store, such as roasts, steaks, chops, or cutlets (these are called retail cuts). The wholesale and retail cuts generated from this process are recognized by the USDA-FSIS as wholemuscle, intact cuts. These products have not been injected, mechanically tenderized, reconstructed, or scored and marinated (US FDA 2009).

Bacteria that can cause serious foodborne illness such as Salmonella and E. coli O157:H7 can live in the digestive tract or on the hide of meat animals and can be transferred to the carcass surface during slaughter (Gill 1979).

However, the interior of these intact cuts (wholesale cuts and retail cuts) remains protected from possible contamination on the surface of the cut, and it is highly unlikely that pathogens would migrate below that surface (USDA-FSIS 1999). During cooking the surface of these intact cuts will almost certainly reach a high enough temperature for a long enough time to terminate any pathogens present (US FDA 2009). Products known to be from intact, whole muscles can safely be consumed after being cooked to medium rare at an internal temperature of $145^{\circ} \mathrm{F}$ and allowing three minutes of additional rest time before consumption (US FDA 2009; USDA-FSIS 2011b).

However, a large percentage of the steaks, roasts, and chops sold at U.S. retail and food service establishments have been subjected to processes to improve their eating quality. Meat products subjected to a process that could possibly introduce pathogens from the surface of the cut into the products' interior are referred to by the USDA-FSIS as non-intact (USDA-FSIS 1999).

Non-intact products include meat that has been pierced with solid or hollow needles and/or blades; injected with solutions via hollow needles; vacuum tumbled, cubed, pounded, or restructured into formed entrees; or has proteolytic enzymes applied to improve tenderness. Generally, water is the primary component of any solution used in meat processing, and salt, phosphate, and an approved flavoring are often added to improve the eating quality of the product.

The FSIS requires any ingredients used in non-intact meat products to be included on the label (USDA-FSIS 2011c). The FDA Food Code Sec. 3-401.11(A)(2) recommends cooking all non-intact meat products to medium at an internal temperature of $160^{\circ} \mathrm{F}$ (US-FDA 2009).

Ground beef and fresh sausage are also non-intact products, but neither are whole-muscle cuts. All ground beef, pork, or lamb products should be cooked to medium at $160^{\circ} \mathrm{F}$, 
and any fresh poultry product should be cooked to $165^{\circ} \mathrm{F}$ as checked by a properly calibrated cooking thermometer in the thickest part of the cut or patty (USDA-FSIS 2011b).

You have probably eaten non-intact, whole-muscle meat products. The USDA-FSIS does not require retail cuts that have only been blade or needle tenderized, without added ingredients, to state that they have been "mechanicallytenderized" on the label. Additionally, a majority of all the steaks and chops sold at food service establishments have been mechanically-tenderized, injected, or vacuum tumbled.

\section{Binding Ingredients Used in Restructured/Formed Fresh Meat}

Many binding ingredients are approved to produce restructured/formed fresh meat products, but two products used extensively in the United States are transglutaminase and fibrin. These binders have been referred to in the media as "meat glue." These binding ingredients are added to small or inconsistently shaped cuts of meat or poultry to bind or re-form them, without the need for heating. This results in larger pieces of meat that can be used for portion-controlled cutting. Restructured or formed fresh meat is recognized by USDA-FSIS as a non-intact product (USDA-FSIS 1999).

Transglutaminase is a natural enzyme, and fibrin is an ingredient made from the protein fibrinogen and the natural enzyme thrombin. All three of these (transglutaminase, fibrinogen, and thrombin) occur in the blood of all animals and humans. These compounds contribute to blood clotting and the healing of wounds in humans and animals (Ofori and Hsieh 2012).

Commercially, transglutaminase is produced by Streptoverticillium mobaraense bacteria, while fibrin is produced from porcine or bovine blood plasma (De Jong et al. 2001). Both transglutaminase and fibrin are listed as GRAS (generally recognized as safe) by the FDA (US FDA 2012).

You have probably eaten a product made from restructured/ formed fresh meat that contained binding ingredients. All products made using either of these binders must be labeled as "formed" or "restructured" meat and the ingredient must be listed on the label (USDA-FSIS 2012b).

Restaurants don't have to label products as "formed" or "restructured" on menus, but, as stated earlier, state or local agencies that enforce the FDA Food Code for food service recommend cooking all non-intact meat products to an internal temperature of $160^{\circ} \mathrm{F}$ (US FDA 2009).

\section{Beef and Pork Derived from Advanced Meat Recovery Systems}

An advanced meat recovery (AMR) system uses a series of belts to scrape, shave, and press meat off bones, but the machinery is not allowed to break or crush the bones (USDA-FSIS 2002). An AMR system can be used for beef and pork bones, but not for poultry because the bones are too delicate and small (USDA-FSIS 2002). Beef and pork derived from an AMR system do not have to be specially labeled because they are similar to hand-deboned meat products (USDA-FSIS 2002).

AMR systems for beef do have certain regulations. Beef AMR products cannot include "specified risk materials" (SRMs), which are the brain, skull, spinal cord, vertebral column, and other central nervous system tissues from cattle 30 months and older (USDA-FSIS 2005b). Thus, beef AMR products cannot be made from the vertebral column of bones and the skull from cattle over 30 months. Beef derived from AMR systems also cannot contain brain, spinal cord, dorsal root ganglia, trigeminal ganglia, or a significant amount of bone solids or marrow, regardless of the age of the animals used to produce the product (USDAFSIS 2005b).

Laboratory work and epidemiological findings suggest that human consumption of infected specified risk materials from an animal with bovine spongiform encephalopathy (BSE), or "Mad Cow" disease, could result in the consumer developing variant Creutzfeldt-Jakob Disease (vCJD; USDA-FSIS 2005a); however, this has never been definitively proven.

Most people have probably consumed AMR beef or pork. As stated earlier, AMR products are recognized by the USDA-FSIS as meat and are not required to be labeled specifically. Beef and pork from AMR processing are often blended with ground products derived from beef or pork trimmings for use in meat patties, links, sausages, chili products, sauces, soup bases, meat gravies, broth, and flavorings (USDA-FSIS 2002).

\section{Mechanically-Separated Poultry and Pork}

Mechanically-separated poultry and pork are made by crushing the bones, then forcing the bone and remaining 
tissue through a screen under high pressure, to sift out the larger pieces of bone, creating a protein batter (USDA-FSIS 2010). This technology is not allowed to be applied to beef products in the United States (USDA-FSIS 2010).

Mechanically-separated pork or poultry can be mixed with other ground meats and functional ingredients. For example, it is used in nuggets and patties, or stuffed into casings to make lunch meats and hot dogs (USDA-FSIS 2010). These products are required to contain less than $1 \%$ bone, as estimated by percent calcium. Also, the USDA states that any processed meat cannot contain more than $20 \%$ mechanically-separated pork or poultry, and any single species pork or poultry processed meat product cannot contain mechanically-separated meat product (USDA-FSIS 2010).

You have probably consumed products made with mechanically-separated poultry or pork, including hot dogs or lunch meat. Mechanically-separated products must be labeled in the ingredients statement as "mechanicallyseparated pork, chicken, or turkey" (USDA-FSIS 2010).

\section{Being an Educated Consumer}

Meat processing technology is used to produce many of the foods we enjoy, such as hot dogs, hamburgers, and chicken nuggets. Now that you know more about the processes used to make these products and the government regulations that must be followed, you can be more informed about the food your family eats. Regardless of the steps needed to get food from the farm to your kitchen, it is important to follow certain food safety guidelines when handling and preparing food.

\section{Safe Handling}

Select fresh meat and poultry when you are at the end of your grocery shopping. Depending on the retailer, there may be a "sell-by" date on the package. Products should be consumed by this date to ensure best quality, but products can be consumed or frozen after the sell-by date (USDAFSIS 2011a).

During transportation, place meat products in an insulated cooler with ice prior to being refrigerated at $40^{\circ} \mathrm{F}$ or lower, once you reach your destination. Preventing temperature abuse will prevent the growth of pathogens if they happen to be present and prevent growth of spoilage bacteria in order to maintain product quality (USDA-FSIS 2011a).

To ensure best quality, red meat steaks and roasts should be cooked or frozen within 3-5 days after purchase. Ground red meat products, organ meats, and poultry should be cooked or frozen within 2 days after purchase (USDA-FSIS 2011a).

Meat should be packaged in material to minimize oxygen exposure during frozen storage, such as vacuum packaging, heavily-waxed freezer paper, or freezer bags. Meat should be arranged within the freezer to optimize air flow, allowing products to freeze as rapidly as possible (USDA-FSIS 2011a).

The less oxygen that meat products are exposed to during storage, the longer products maintain frozen quality. More guidelines for suggested frozen storage and proper thawing procedures are available (see http://www.fsis.usda.gov/ Fact_Sheets/Big_Thaw/ for more information) (USDA-FSIS 2011a).

Always use safe handling methods with raw meat, such as washing hands and surfaces with hot, soapy water to avoid cross-contamination. Surfaces and utensils may be sanitized with a diluted bleach solution (USDA-FSIS 2011a).

\section{Summary}

The meat we eat comes in many forms, but each meat product sold in the United States must meet the inspection standards of the USDA-FSIS. You should stay informed about food processing techniques and ingredients so you can make the best decisions for your family. Gather all the facts to make an informed decision about the food you eat.

\section{References}

Beef Products, Inc. (BPI). 2012. "Making Lean Beef." Accessed November 2012. http://www.beefproducts.com/ our_commitment.php.

Berry, B. W. 1980. "Effects of Chopping versus Grinding on Palatability, Shear, Chemical and Cooking Properties of Beef Patties." J. Anim. Sci. 51:615-9.

Cargill Meat Solutions. 2012. "About Finely Textured Beef." Accessed November 2012. http://www.cargill.com/news/ company-statements/cargill-finely-textured-beef/index.jsp.

De Jong, G.A.H., G. Wijngaards, H. Boumans, S. J. Koppelman, and M. Hessing. 2001. "Purification and Substrate Specificity of Transglutaminases from Blood and Streptoverticillium mobaraense." J Agric Food Chem 49:3389-93.

Gill, C. O. 1979. "Intrinsic Bacteria in Meat." J. Applied Bacteriology 47:367-78. 
Greene, J. L. 2012. "Lean Finely Textured Beef: The 'Pink Slime' Controversy." Congressional Research Service, USDA. Accessed November 2012. http://www.fas.org/sgp/ crs/misc/R42473.pdf.

Ofori, J. A., and Y. H. P. Hsieh. 2012. "The Use of Blood and Derived Products as Food Additives." In Food Additive, edited by Y. El-Samragy. Accessed November 2012. http:// cdn.intechopen.com/pdfs/28918/InTech-The_use_of_ blood_and_derived_products_as_food_additives.pdf.

Roth, E. 1978. Method for forming frozen meat patties. US Patent 4192899, filed September 11, 1978, and issued March 11, 1980.

Schaefer, D.L., R. M. James, and M. E. Rempe. 1995. Low temperature rendering process. US Patent 5725897, filed July 25, 1995, and issued March 10, 1998.

United States Food and Drug Administration (US FDA). 2012. "Generally Recognized as Safe (GRAS)." Accessed November 2012. http://www.fda.gov/Food/FoodIngredientsPackaging/GenerallyRecognizedasSafeGRAS/default. htm.

US FDA. 2009. "FDA Food Code." Accessed November 2012. http://www.fda.gov/downloads/Food/FoodSafety/RetailFoodProtection/FoodCode/FoodCode2009/ UCM189448.pdf.

The United States Department of Agriculture Food Safety and Inspection Service (USDA-FSIS). 2012a. "Inspection for Food Safety: The Basics.” Accessed November 2012. http://www.fsis.usda.gov/fact_sheets/Inspection_for_Food_ Safety_the_Basics/index.asp.

USDA-FSIS. 2012b. "Safety of Transglutaminase Enzyme (TG enzyme).” Accessed November 2012. http://www.fsis. usda.gov/fact_sheets/Safety_TG_Enzyme/index.asp.

USDA-FSIS. 2011a. "Basics for Handling Food Safely." Accessed November 2012. http://www.fsis.usda.gov/ Fact_Sheets/Basics_for_Handling_Food_Safely/index.asp.

USDA-FSIS. 2011b. "Is It Done Yet?" Accessed November 2012. http://www.fsis.usda.gov/Is_It_Done_Yet/Brochure_Text/index.asp.

USDA-FSIS. 2011c. "Meat Preparation: Water in Meat and Poultry." Accessed November 2012. http://www.fsis.usda. gov/Fact_Sheets/Water_in_Meats/index.asp.
USDA-FSIS. 2010. "Meat Preparation: Hot Dogs and Food Safety." Accessed November 2012. http://www.fsis.usda.gov/ Fact_Sheets/Hot_Dogs/index.asp.

USDA-FSIS. 2009. "Production \& Inspection: FSIS Import Procedures for Meat, Poultry \& Egg Products." Accessed November 2012. http://www.fsis.usda.gov/Fact_Sheets/ FSIS_Import_Procedures/index.asp.

USDA-FSIS. 2008. "Compliance Guide on the Determination of Processing Aids." Accessed November 2012. http:// www.fsis.usda.gov/pdf/determination_of_processing_aids. pdf.

USDA-FSIS. 2005a. "Production \& Inspection: Bovine Spongiform Encephalopathy: 'Mad Cow Disease.” Accessed November 2012. http://www.fsis.usda.gov/FactSheets/ Bovine_Spongiform_Encephalopathy_Mad_Cow_Disease/ index.asp.

USDA-FSIS. 2005b. "Production \& Inspection: FSIS Further Strengthens Protections Against Bovine Spongiform Encephalopathy (BSE)." Accessed November 2012. http:// www.fsis.usda.gov/FactSheets/FSIS_Further_Strengthens_Protections_Against_BSE/index.asp.

USDA-FSIS. 2002. "Revised Directive for Advanced Meat Recovery Systems." Accessed November 2012. http://www. fsis.usda.gov/Oa/background/amrdirec.htm.

USDA-FSIS. 1999. "FSIS Policy on Non-Intact Raw Beef Products Contaminated with E. coli O157:H7." Accessed November 2012. http://www.fsis.usda.gov/oa/background/ O157policy.htm.

\section{Recommended Websites}

United States Department of Agriculture Food Safety and Inspection Service (http://www.fsis.usda.gov/): Provides information about meat, poultry, and egg products' safety and packaging. 